Marta Biedka1 , Tamara Kuźba-Kryszak², Łukasz Wicherek², Magdalena Dutsch-Wicherek ${ }^{3}$

${ }^{1}$ Department of Oncology and Brachytherapy Ludwik Rydygier Collegium Medicum in Bydgoszcz, Nicolaus Copernicus University, Bydgoszcz, Poland

${ }^{2}$ Chair of Oncology, Radiotherapy, and Gynaecological Oncology, Ludwik Rydygier Collegium Medicum in Bydgoszcz,

Nicolaus Copernicus University, Bydgoszcz, Poland

${ }^{3}$ Department of Paediatric Otolaryngology, Chair of Paediatrics, Jagiellonian University Medical College, Kraków, Poland

\title{
The analysis of the level of Treg lymphocytes in the blood of patients with endometrial cancer before and after the surgery - preliminary study
}

\author{
Corresponding author: \\ Dr. hab. n. med. \\ Magdalena Dutsch-Wicherek \\ Department of Paediatric \\ Otolaryngology, Chair of Paediatrics, \\ Jagiellonian University Medical College \\ Wielicka 265 St., 30-663, Kraków \\ Poland \\ E-mail: \\ magdalena.dutsch-wicherek@uj.edu.pl
}

Medical Research Journal 2017;

Volume 2, Number 3, 97-101

10.5603/MRJ.2017.0012

Copyright (C) 2017 Via Medica

ISSN 2451-2591

\begin{abstract}
Introduction. The progression of cancer is a complex process involving host-tumour interactions taking place in cancer and in the cancer microenvironment. The tumour remodels the microenvironment into the suppressive profile by various mechanisms. One of the most important elements of this mechanism is the inducing of the infiltration of Treg lymphocytes into cancer and its microenvironment. The aim of the present study was to evaluate the alterations of the Treg cell population in the peripheral blood of patients before and after the surgical treatment for endometrial cancer.

Material and methods. For the present study 24 patients with endometrial cancer were recruited. All the patients were treated surgically. The peripheral blood samples were collected from the endometrial cancer patients before operation and three days after the surgical procedure and evaluated using flow cytometry method.

Results. CD25 + CD4 + FOXP3 + T cells were found in all the examined peripheral blood samples derived from the endometrial cancer patients in the days before and following applied surgery. We observed differences before and after the applied surgical procedure in patients treated for uterine cancer. The highest number of Treg cells in the peripheral blood was demonstrated before the surgical procedure; it diminished statistically significantly following the surgery.

Conclusions. The decrease of the percentage of Treg cells in blood sera in patients following radical surgical treatment might be useful in measuring the radicalism of the treatment. The monitoring of the level of selective immune system suppression related to Treg cell blood serum levels during cancer therapy might support a decision to supplement the standard therapy with immunotherapy or to increase the degree of radicalism of the applied therapy.

Key words: Treg lymphocytes, endometrial cancer
\end{abstract}

Med Res J 2017; 2 (3): 97-101

\section{Introduction}

The progression of cancer is a complex process involving the host-tumour interactions taking place in cancer and in cancer microenvironment. The tumour remodels the microenvironment into the suppressive profile by various mechanisms. One of the most important elements of this mechanism is the inducing of the infiltration of Treg lymphocytes into cancer and its microenvironment. The association between tu- mour-infiltrating lymphocytes (TIL) and patient survival has been demonstrated in many cancer studies [1-3]. The classification of $\mathrm{CD} 3+\mathrm{T}$ cells into functional subsets has led to the subdivision of cytotoxic lymphocytes and regulatory lymphocytes. TIL with cytotoxic markers are linked with favourable prognosis, while TIL-expressing regulatory markers (Tregs) are related with poor prognosis $[4,5]$. At the beginning Tregs were defined by such molecular markers as CD4+ and CD25+ [6]. Further studies demonstrated that Tregs express and 
functionally depend on the transcription factor forkhead box protein P3 (FoxP3) [7]. FoxP3 is a well-accepted marker for Treg cells in cancer studies $[7,8]$. There are two main subsets of Treg cells: naturally occurring, thymic-derived CD4+Treg cells and peripherally antigen-induced CD4+ T cells derived from CD4+CD25 non-Treg cells. Regulatory T cells comprise approximately $5-10 \%$ of CD4+ T cells [9-13] CD4+CD25+ regulatory T cells (Tregs), which express the transcription factor FOXP3, suppress cytotoxic immune response, effector T-cell populations including CD4+, CD8+ T cells, dendritic cells, macrophages, and natural killer cells (NK) [9-13], and can enable tumour cells to evade the host immune response. Increased numbers of CD4+FOXP3+CD25 high Treg as well as high levels of suppressor function have been observed in the tissue of various human carcinomas as well as in the peripheral circulation of cancer patients. Treg accumulations in cancer have been generally linked with unfavourable disease outcome as reported for many human solid tumours [4, 14-17]. It was proposed that high Foxp3 expression level may become a marker for an immunosuppression level contributing to tumour immune escape [14, 15]. In the invasive front of cervical cancer Foxp3-expressing $T$ cells were associated with invasion and metastasis [19-24]. The malignant neoplasm destroys, therefore, the host immune response, and the surgical treatment aims to remove the tumour mass radically and to restore the immune response. It was demonstrated that when the degree of surgery radicalism increases the possibility of restoring the immune function also increases [25-27]. There is no efficient method for the evaluation of surgical treatment radicalism. Because Treg cells are the main cell population that enables cancer cells to escape immune surveillance, the Treg cell population might correspond to a diminishment of the tumour mass in patients and might therefore be a marker of the intensity of the selective suppression of the host immune system and also of the degree of radicalism of the surgical procedure.

The aim of the present study was to evaluate the alterations of the Treg cell population in the peripheral blood of patients before and after surgical treatment for endometrial cancer.

\section{Material and methods}

\section{Patients}

The 24 patients included in the study were treated surgically for endometrial cancer between November 2014 and December 2015 in the Department of Gynaecology and Oncology of the Lukaszczyk Oncological Centre, Bydgoszcz, Poland. The clinical characteristics of patients group are presented in Table 1.
Table 1. Characteristics of the patients with endometrial cancer

\begin{tabular}{|c|c|}
\hline & $\begin{array}{c}\text { Number } \\
\text { of patients }\end{array}$ \\
\hline Age & $\begin{array}{c}60.4 \\
\text { (range } 40-82 \text { ) }\end{array}$ \\
\hline Co-morbidities & $21(84 \%)$ \\
\hline $\begin{array}{l}\text { Tumour stage according TNM } 2010 \\
\text { T in situ } \\
\text { T1a } \\
\text { T1b } \\
\text { T2 } \\
\text { T3 }\end{array}$ & $\begin{array}{c}1(2.5 \%) \\
13(52 \%) \\
6(24 \%) \\
3(12 \%) \\
1(2.5 \%)\end{array}$ \\
\hline $\begin{array}{l}\text { Lymph node status according } 2010 \\
\text { Without lymph node involvement - N0 } \\
\text { Presence lymph node metastases - N1 }\end{array}$ & $\begin{array}{c}22(88 \%) \\
3(12 \%)\end{array}$ \\
\hline $\begin{array}{l}\text { Distant metastases wg TNM } 2010 \\
\text { M0 absent } \\
\text { M1 present }\end{array}$ & $\begin{array}{c}25(100 \%) \\
0(0 \%)\end{array}$ \\
\hline $\begin{array}{l}\text { Tumour differentiation grade } \\
\text { Grade } 1 \\
\text { Grade } 2 \\
\text { Grade } 3\end{array}$ & $\begin{array}{c}4(10 \%) \\
20(80 \%) \\
1(2.5 \%)\end{array}$ \\
\hline $\begin{array}{l}\text { Histopathological assessment } \\
\text { Adenocarcinoma } \\
\text { Adenosarcoma } \\
\text { Carcinoma in situ }\end{array}$ & $\begin{array}{l}23(92 \%) \\
1(4 \%) \\
1(4 \%)\end{array}$ \\
\hline $\begin{array}{l}\text { After operation margin } \\
\quad>1 \mathrm{~cm} \\
<1 \mathrm{~cm} \\
<0.5 \mathrm{~cm} \\
\text { Unknown }\end{array}$ & $\begin{aligned} 22 & (88 \%) \\
1 & (4 \%) \\
1 & (4 \%) \\
1 & (4 \%)\end{aligned}$ \\
\hline $\begin{array}{l}\text { Kind of treatment } \\
\text { Operation } \\
\text { Brachytherapy } \\
\text { Radiotherapy } \\
\text { Chemotherapy }\end{array}$ & $\begin{array}{l}25(100 \%) \\
21(84 \%) \\
2(8 \%) \\
2(8 \%)\end{array}$ \\
\hline $\begin{array}{l}\text { Response for treatment } \\
\text { CR complete response } \\
\text { PR partial response } \\
\text { SD stabile disease } \\
\text { PD progression disease } \\
\text { Death } \\
\text { Recurrence }\end{array}$ & $\begin{array}{l}23(92 \%) \\
0(0 \%) \\
0(0 \%) \\
0(0 \%) \\
2(8 \%) \\
1(4 \%)\end{array}$ \\
\hline
\end{tabular}

Patients were treated in line with the accepted management standard; in most cases, this included combination treatment. The surgical treatment was applied primarily in all the patients before the combination treatment, which included radiotherapy, brachytherapy, and chemotherapy. Radiotherapy was delivered to the pelvis in three patients, 20 patients underwent a brachytherapy, and three required systemic treatment. External beam irradiation was delivered at doses of $50.4 \mathrm{~Gy}$ in 28 fractions. High-dose rate (HDR) brachytherapy was performed in 20 patients at doses of 10-30 Gy divided into 1-4 fractions. After completion 
of the treatment, response was observed in 21 patients; three of the patients included to our group died because of the progression of uterine cancer. Follow-up visits were held four weeks after completion of treatment and then at three-month intervals. Patient follow-up lasted at least 12 months.

The peripheral blood samples were collected from the endometrial cancer patients before operation and three days after the surgical procedure. The patient's consent was obtained in each case.

\section{Flow cytometry}

The samples for the cytometric analysis of the Treg cell population in the whole blood of patients were prepared using Human Regulatory $\mathrm{T}$ Cell Staining Kits (eBioscience), according to the manufacturer's instruction with some minor modifications. To the $100 \mu \mathrm{L}$ of blood, $15 \mu \mathrm{L}$ of CD4 FITC and CD25 PE cocktail, as well as $5 \mu \mathrm{L}$ of CD45 APC-Cy7 (Becton Dickinson; BD Biosciences Pharmingen, San Jose, CA, USA), were added. After $30 \mathrm{~min}$ of incubation with mAbs (in the dark at $4^{\circ} \mathrm{C}$ ), the cells were washed with Flow Cytometry Staining Buffer, centrifuged for $5 \mathrm{~min}$ at $350 \times \mathrm{g}$, and then permeabilised with freshly prepared fixation/permeabilisation buffer (for $40 \mathrm{~min}$ in the dark at $4^{\circ} \mathrm{C}$ ). Next, the cells were washed twice by adding $1 \times$ permeabilisation buffer, blocked by normal rat serum (for $15 \mathrm{~min}$ in the dark at $40^{\circ} \mathrm{C}$ ) and subsequently stained with anti-human FoxP3 APC antibody or rat IgG2a $\kappa$ APC antibody (in the case of isotype control) for $35 \mathrm{~min}$ in the dark at $40^{\circ} \mathrm{C}$. After another washing step, the cells were suspended in Flow Cytometry Staining Buffer and analysed using a BD FACS Canto II flow cytometer and BD FACS Diva Software (Becton Dickinson). In each sample, $3 \times 104$ lymphocytes were collected and gated on SSC $\times$ CD45 APC-Cy7 dot-plot. Next, the populations of CD4+ FITC, CD25+ PE, and double positive CD4 and CD25 cells were distinguished among the lymphocytes. Finally, the gate of FoxP3 positive cells was established on the CD4+/CD25+ subpopulation. For each sample, a negative control was performed to measure autofluorescence, and an isotype control was performed to exclude non-specific staining of specific antibodies.

\section{Statistical analysis}

The distribution of variables in the study groups of women checked with the use of the Shapiro-Wilk test showed that each of the women was different from normal. The statistical significance between the groups was determined by the Kruskal-Wallis test, one-way analysis of variance by ranks. The Mann-Whitney $U$ test was then used as applicable. All statistical analyses were carried out with the Statistica 8.0 software program (StatSoft Inc.,
Tulsa, OK, USA). A p value $<0.05$ was considered indicative of statistical significance.

\section{Results}

CD25+ CD4+ FOXP3 + T cells were found in all the examined peripheral blood samples derived from the endometrial cancer patients in the days before and following applied surgery. We observed differences before and after the surgical procedure in patients treated for endometrial cancer. The highest number of Treg cells in the peripheral blood was demonstrated before the surgical treatment; it diminished statistically significantly following the surgery.

1. The percentage of Foxp3-positive cells within CD4+ lymphocytes was statistically significantly higher in patients with endometrial cancer before the surgery than after the surgery $(p<0.05)$.

2. No statistically significant differences in the percentage of CD4+CD25+ positive lymphocytes within the population of CD4+ lymphocytes were observed in relation with the surgery - Figure 1.

3. A statistically significant decrease in the percentage of CD4+CD25+ positive lymphocytes within the population of $\mathrm{T}$ lymphocytes was observed following the surgery $(p<0.05)$.

4. A statistically significant decrease in the percentage of Foxp3+ lymphocytes within the population of CD4+CD25+ following the surgical treatment was observed $(p<0.003)$ - Figure 2.

5. A statistically significant decrease in the percentage of Foxp3+ lymphocytes within the population of CD4+ $(p<0.05)$ was observed following the surgical treatment.

No statistically significant differences were identified between the analysed antigens and the age, haemoglobin level, white blood cells, platelet count, the type of the treatment applied before the surgery such as radiotherapy, brachytherapy, concomitant diseases, T-staging, FIGO classification, tumour differentiation grade $\mathrm{G}$, lymph node status, and presence of lesions in the cervix.

\section{Discussion}

In the present study it was demonstrated that surgical treatment in endometrial cancer influences significantly the percentages of T lymphocyte subpopulations in blood sera. Statistically significant decreases of the percentage of Foxp3+CD4+CD25+ lymphocytes within the population of CD4+CD25+ lymphocytes and within the population of CD4+ T lymphocytes were observed following the surgical treatment. A similar observation was noted in ovarian cancer, where the 


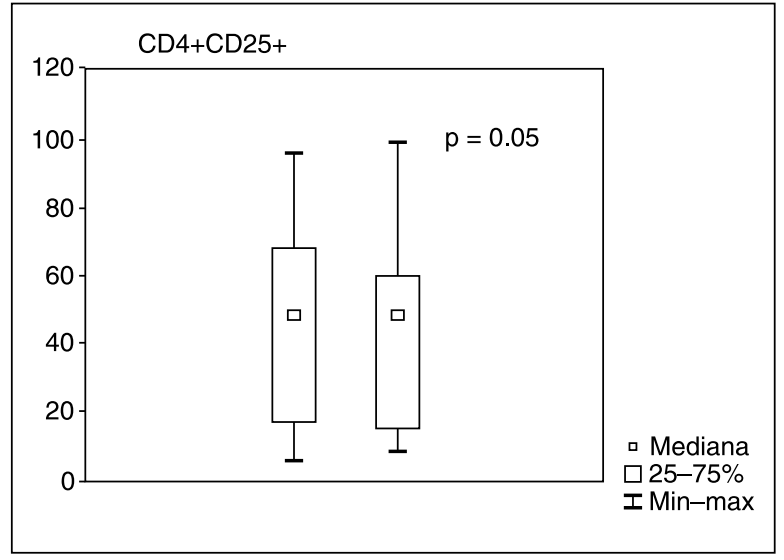

Figure 1. The percentage of CD4+CD25+ positive lymphocytes within the population of CD4+ lymphocytes in relation with the surgery. No statistically significant differences were observed in the percentage of CD4+CD25+ positive lymphocytes within the population of CD4+ positive lymphocytes with respect to the surgery

percentages of FOXP3 + cells in the subpopulation of CD4+ T lymphocytes found in the peripheral blood of the patients before the surgical procedure were statistically significantly higher than those observed in the peripheral blood of the same patients after the surgical procedure [27]. The suppressive microenvironment in endometrial cancer is thus created by the recruitment of Treg cells into the tumour and its stroma and leads to an increase of the percentage of Treg cell population in the blood serum observed in various cancer patients $[7,8]$. In murine models, depletion of Treg cells was observed to promote tumour rejection or inhibit the tumour growth $[28,29]$. In uterine cancer, the frequency of Treg cells in peripheral blood mononuclear cells in blood serum was prominently increased, independently of the stage of disease $[28,29]$.

The decrease of the percentage of Treg cells in blood sera in patients following radical surgical treatment might be useful in measuring the radicalism of the treatment. The monitoring of the level of selective immune system suppression related to Treg cell blood serum levels during cancer therapy might support a decision to supplement the standard therapy with immunotherapy or to increase the degree of radicalism of the applied therapy.

\section{References}

1. Leffers N, Gooden MJM, de Jong RA, et al. Prognostic significance of tumor-infiltrating T-lymphocytes in primary and metastatic lesions of advanced stage ovarian cancer. Cancer Immunol Immunother 2009; 58(3): 449-459, doi: 10.1007/s00262-008-0583-5, indexed in Pubmed: 18791714

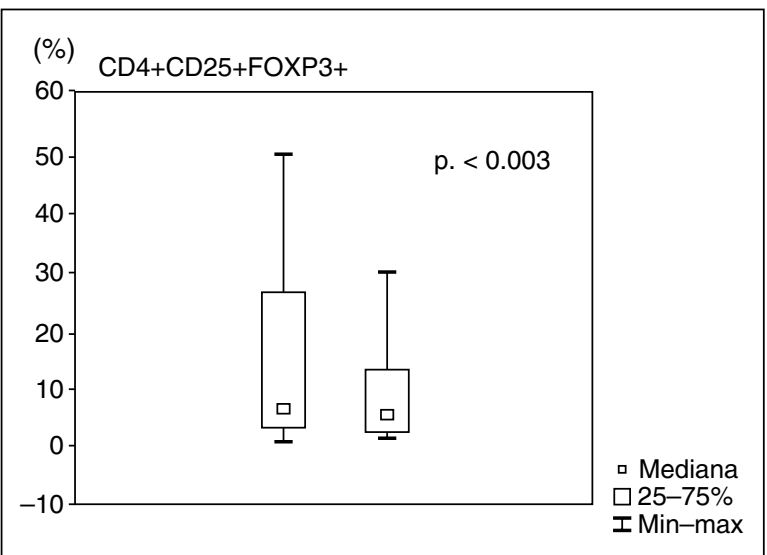

Figure 2. The percentage of Foxp3+ lymphocytes within the population of CD4+CD25+ positive lymphocytes in relation with the surgery. The statistically significant decrease in the percentage of Foxp3 positive lymphocytes was observed following the surgical treatment

2. Sato E, Olson $\mathrm{SH}, \mathrm{Ahn}$ J, et al. Intraepithelial CD8+ tumor-infiltrating lymphocytes and a high CD8+/regulatory $\mathrm{T}$ cell ratio are associated with favorable prognosis in ovarian cancer. Proc Natl Acad Sci USA. 2005; 102(51): 18538-18543, doi: 10.1073/pnas.0509182102, indexed in Pubmed: 16344461.

3. Zhang YL, Li J, Mo HY, et al. Different subsets of tumor infiltrating lymphocytes correlate with NPC progression in different ways. Mol Cancer. 2010; 9: 4, doi: 10.1186/1476-4598-9-4, indexed in Pubmed: 20064222.

4. Curiel TJ, Coukos G, Zou L, et al. Specific recruitment of regulatory T cells in ovarian carcinoma fosters immune privilege and predicts reduced survival. Nat Med. 2004; 10(9): 942-949, doi: 10.1038/nm1093, indexed in Pubmed: 15322536.

5. Barnett B, Kryczek I, Cheng P, et al. Regulatory T cells in ovarian cancer: biology and therapeutic potential. Am J Reprod Immunol. 2005; 54(6): 369-377, doi: 10.1111/j.1600-0897.2005.00330.x, indexed in Pubmed: 16305662

6. Shevach EM. CD4 + CD25+ suppressor T cells: more questions than answers. Nat Rev Immunol. 2002; 2(6): 389-400, doi: 10.1038/nri821, indexed in Pubmed: 12093005.

7. Sakaguchi S, Yamaguchi T, Nomura T, et al. Regulatory T Cells and Immune Tolerance. Cell. 2008; 133(5): 775-787, doi: 10.1016/j. cell.2008.05.009.

8. Sakaguchi S, Ono M, Setoguchi R, et al. Foxp3+ CD25+ CD4+ natural regulatory $\mathrm{T}$ cells in dominant self-tolerance and autoimmune disease. Immunol Rev. 2006; 212: 8-27, doi: 10.1111/j.01052896.2006.00427.x, indexed in Pubmed: 16903903

9. Hamidinia M, Ghafourian Boroujerdnia M, Talaiezadeh A, et al. Increased P-35, EBI3 transcripts and other Treg markers in peripheral blood mononuclear cells of breast cancer patients with dfferent clinical stages. Adv Pharm Bull. 2015; 5(2): 261-267, doi: 10.15171/apb.2015.036, indexed in Pubmed: 26236666.

10. Gavin MA, Rasmussen JP, Fontenot JD, et al. Foxp3-dependent programme of regulatory T-cell differentiation. Nature. 2007; 445(7129): 771-775, doi: 10.1038/nature05543, indexed in Pubmed: 17220874

11. Hori S, Nomura T, Sakaguchi $S$, et al. Control of regulatory $T$ cell development by the transcription factor Foxp3. Science. 2003; 299(5609): 1057-1061, doi: 10.1126/science.1079490, indexed in Pubmed: 12522256

12. Fontenot JD, Rasmussen JP, Gavin MA, et al. A function for interleukin 2 in Foxp3-expressing regulatory T cells. Nat Immunol. 2005; 6(11): 1142-1151, doi: 10.1038/ni1263, indexed in Pubmed: 16227984

13. Collison LW, Workman CJ, Kuo TT, et al. The inhibitory cytokine IL-35 contributes to regulatory T-cell function. Nature. 2007; 450(7169): 566-569, doi: 10.1038/nature06306, indexed in Pubmed: 18033300.

14. Whiteside TL. What are regulatory T cells (Treg) regulating in cancer and why? Semin Cancer Biol. 2012; 22(4): 327-334, doi: 10.1016/j. semcancer.2012.03.004, indexed in Pubmed: 22465232. 
15. Whiteside TL. Clinical impact of regulatory T cells (Treg) in cancer and HIV. Cancer Microenviron. 2015; 8(3): 201-207, doi: 10.1007/s12307014-0159-1, indexed in Pubmed: 25385463.

16. Petersen RP, Campa MJ, Sperlazza J, et al. Tumor infiltrating Foxp3+ regulatory T-cells are associated with recurrence in pathologic stage I NSCLC patients. Cancer. 2006; 107(12): 2866-2872, doi: 10.1002/cncr.22282, indexed in Pubmed: 17099880.

17. Bates GJ, Fox SB, Han C, et al. Quantification of regulatory $T$ cells enables the identification of high-risk breast cancer patients and those at risk of late relapse. J Clin Oncol. 2006; 24(34): 5373-5380, doi: 10.1200/JCO.2006.05.9584, indexed in Pubmed: 17135638

18. Feng $\mathrm{LL}$, Wang $X$. Targeting Foxp3+ regulatory $T$ cells-related immunosuppression for cancer immunotherapy. Chin Med J (Engl). 2010; 123(22): 3334-3342, indexed in Pubmed: 21163140.

19. Nakamura T, Shima T, Saeki Ai, et al. Expression of indoleamine 2, 3-dioxygenase and the recruitment of Foxp3-expressing regulatory T cells in the development and progression of uterine cervical cancer. Cancer Sci. 2007; 98(6): 874-881, doi: 10.1111/j.1349-7006.2007.00470.x indexed in Pubmed: 17433037.

20. Zeng $\mathrm{C}, \mathrm{Yao} \mathrm{Y}$, Jie $\mathrm{W}$, et al. Up-regulation of Foxp3 participates in progression of cervical cancer. Cancer Immunol Immunother. 2013; 62(3): 481-487, doi: 10.1007/s00262-012-1348-8, indexed in Pubmed: 22986453

21. Zhang $Y, M a D, Z$ hang $Y$, et al. The imbalance of Th17/Treg in patients with uterine cervical cancer. Clin Chim Acta. 2011; 412(11-12): 894-900, doi: 10.1016/j.cca.2011.01.015, indexed in Pubmed: 21255562.
22. Griffiths RW, Elkord E, Gilham DE, et al. Frequency of regulatory T cells in renal cell carcinoma patients and investigation of correlation with survival. Cancer Immunol Immunother. 2007; 56(11): 1743-1753, doi: 10.1007/s00262-007-0318-z, indexed in Pubmed: 17487490

23. Miller AM, Lundberg $\mathrm{K}$, Ozenci $\mathrm{V}$, et al. CD4+CD25high $\mathrm{T}$ cells are enriched in the tumor and peripheral blood of prostate cancer patients. J Immunol. 2006; 177(10): 7398-7405, indexed in Pubmed: 17082659.

24. Whiteside TL, Mandapathil M, Szczepanski M, et al. Mechanisms of tumor escape from the immune system: adenosine-producing Treg, exosomes and tumor-associated TLRs. Bull Cancer. 2011; 98(2): E25-E31, doi: 10.1684/bdc.2010.1294, indexed in Pubmed: 21339097.

25. Salvadori S, Martinelli G, Zier K. Resection of solid tumors reverses $T$ cell defects and restores protective immunity. J Immunol. 2000; 164(4): 2214-2220, indexed in Pubmed: 10657677.

26. Cole WH, Humphrey L. Need for immunologic stimulators during immunosuppression produced by major cancer surgery. Ann Surg 1985; 202(1): 9-20, indexed in Pubmed: 3893336.

27. Wicherek L, Jozwicki W, Windorbska W, et al. Analysis of Treg cell population alterations in the peripheral blood of patients treated surgically for ovarian cancer — a preliminary report. Am J Reprod Immunol. 2011; 66(5): 444-450, doi: 10.1111/j.1600-0897.2011.01024.x, indexed in Pubmed: 21624000.

28. Zhang L, Conejo-Garcia JR, Katsaros D, et al. Intratumoral T cells, recurrence, and survival in epithelial ovarian cancer. N Engl J Med. 2003; 348(3) 203-213, doi: 10.1056/NEJMoa020177, indexed in Pubmed: 12529460.

29. Zhang P, Côté $A L$, de Vries VC, et al. Induction of postsurgical tumor immunity and T-cell memory by a poorly immunogenic tumor. Cancer Res. 2007; 67(13): 6468-6476, doi: 10.1158/0008-5472.CAN-07-1264, indexed in Pubmed: 17616708. 